\title{
Main-Chain Polymers with Nonlinear Optical Chromophores as a Slipped Shoulder-to-Shoulder Arrangement
}

\author{
Yadong Zhang, ${ }^{*}$ Tatsuo WAdA, ${ }^{*, * *+}$ Liming WANG, ${ }^{* *}$ and Hiroyuki SASABE ${ }^{*, * *}$ \\ * Core Research for Evolutional Science and Technology (CREST), JST, \\ ** Frontier Research Program, The Institute of Physical and Chemical Research (RIKEN), \\ Hirosawa 2-1, Wako, Saitama 351-01, Japan
}

(Received January 29, 1997)

\begin{abstract}
New second-order nonlinear optical main-chain polymers have been synthesized in very high yields by a two-stage Knoevenagel polycondensation from 3,6-diformyl-9-heptylcarbazole and bis(cyanoacetate)s. In these main-chain polymers, two kinds of nonlinear optical (NLO) chromophores, carbazole with two acceptor groups and $4^{\prime}$-nitrophenylazoaniline, were introduced in a slipped shoulder-to-shoulder arrangament. All polymers were determined to be amorphous and to have glass transition temperatures in the range of $134-158^{\circ} \mathrm{C}$ by a differential scanning calorimeter. The chloroform soluble main-chain polymers show very high weight and number average molecular weights measured by a gel permeation chromatography. Thin films of the polymers could be obtained by a spin coating method. The orientation of dipoles could be achieved by applying an electric field. These poled films show good reasonable and stable second-order nonlinear optical responses.
\end{abstract}

KEY WORDS Main-Chain Polymer / Slipped Shoulder-to-Shoulder / High Density of Nonlinear Optical Chromophores / Multifunctional Materials / Two-Stage Knoevenagel Polycondensation / Second Harmonic Generation /

Recently, organic nonlinear optical (NLO) polymers have attracted considerable interest due to their potential applications in integrated electro-optic devices. ${ }^{1}$ Several molecular design strategies have been developed for the synthesis of NLO polymers, such as guest host systems (NLO chromophores doped in host matrix), ${ }^{2-4}$ sidechain systems (NLO chromophores attached as a side chain), ${ }^{5-9}$ and main-chain systems (NLO chromophores incorporated as a part of main chain). ${ }^{10-15}$ The secondorder NLO responses of these polymer systems could be achieved after the alignment of dipole chromophores by applying an electric field. It is well known that the value of the second-order nonlinearity is mainly dependent on three factors: molecular hyperpolarisability $(\beta)$ of a chromophore, density of a chromophore and the degree of electric field-induced alignment. Generally, polymers with a high percentage of NLO chromophores have a large macroscopic second-order NLO response. In order to reach a maximum concentration of NLO chromophores, NLO moieties with suitable arrangements should be linked with a small spacer to polymeric main chain or side chain. ${ }^{13,16}$

Recently, we developed a new synthetic approach to polymers with high densities of NLO chromophores. ${ }^{17}$ In this approach, the NLO chromophores are incorporated into a polymeric main chain and two kinds of chromophores are introduced in a slipped shoulder-toshoulder arrangement (as shown in Figure 1). This style might be a suitable arrangement for providing a new approach to the design and synthesis of new mainchain polymers with high densities of NLO chromophores. The polar alignment of NLO chromophores should be easier to be achieved by applying an electric field than in the structures where their dipole moments are pointing along the polymeric main chain. In this paper, we report the synthesis and nonlinear optical

\footnotetext{
† To whom all correspondence should be addressed.
}

properties of new main-chain polymers. Two kinds of NLO chromophores, carbazole substituted with two acceptor groups and 4'-nitrophenylazoaniline, were used as synthetic building blocks and arranged as a slipped shoulder-to-shoulder style. It is well known that carbazole compounds with both photoconductive ${ }^{18}$ and second-order nonlinear optical ${ }^{19,20}$ properties have been used as an important component for photorefractive materials. ${ }^{21-31}$ Based on the carbazole building block, we recently synthesized several types of carbazole materials, such as main-chain polymers containing carbazole substituted with two acceptor groups ${ }^{25}$ mainchain polymers containing carbazole substituted with one acceptor group, ${ }^{26,27}$ hyperbranched polymers, ${ }^{28,29}$ and conjugated carbazole oligomer. ${ }^{30,31}$ The results indicate that these materials have multifunctional properties and they can be used as a good candidate for photonic applications.

\section{EXPERIMENTAL}

\section{Materials}

$N, N$-Dimethylformamide (DMF) was dried over molecular sieves $3 \AA 1 / 8$. All other solvents and chemicals were used as received.

\section{Preparation of Monomer}

9-Heptylcarbazole 3. To a solution of $100 \mathrm{~g}(0.60 \mathrm{~mol})$ of carbazole 1, $110 \mathrm{~g}(0.61 \mathrm{~mol})$ of 1-heptyl bromide 2

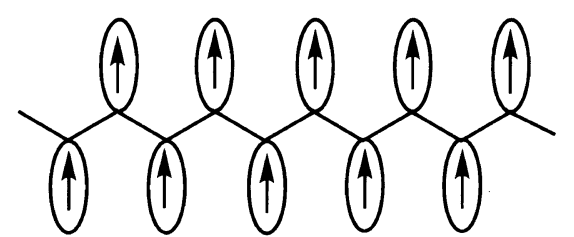

Figure 1. Chromophore alignment (slipped shoulder-to-shoulder arrangement) in main chain polymer after electric poling. 
and $2 \mathrm{~g}$ of benzytriethylammonium chloride in $500 \mathrm{ml}$ of benzene was added $100 \mathrm{~g}$ of sodium hydroxide in $100 \mathrm{ml}$ of water. The reaction mixture was heated to reflux and kept at reflux for $6 \mathrm{~h}$. The reaction mixture was added to $1000 \mathrm{ml}$ of water. The organic layer was separated, and then benzene was removed. The crude product obtained could be used in the next step. ${ }^{1} \mathrm{H}$ NMR $\left(\mathrm{CDCl}_{3} /\right.$ tetramethylsilane (TMS)): $\delta(\mathrm{ppm})=8.09\left(2 \mathrm{H}, \mathrm{d}, \mathrm{H}_{\mathrm{cz}}\right)$, $7.35-7.47\left(4 \mathrm{H}, \mathrm{m}, \mathrm{H}_{\mathrm{cz}}\right), 7.18-7.24\left(2 \mathrm{H}, \mathrm{m}, \mathrm{H}_{\mathrm{cz}}\right), 4.25$ $\left(2 \mathrm{H}, \mathrm{t}, \mathrm{NCH}_{2}\right), 1.84\left(2 \mathrm{H}, \mathrm{m}, \mathrm{CH}_{2}\right), 1.29\left(8 \mathrm{H}, \mathrm{m}, 4 \times \mathrm{CH}_{2}\right)$, $0.84\left(3 \mathrm{H}, \mathrm{t}, \mathrm{CH}_{3}\right)$.

3,6-Diformyl-9-heptylcarbazole 4. To $54 \mathrm{~g}(0.76 \mathrm{~mol})$ of $\mathrm{DMF}$ at $0^{\circ} \mathrm{C}, 116 \mathrm{~g}(0.76 \mathrm{~mol})$ of phosphorus oxychloride was added dropwise. The mixture was allowed to warm up to room temperature, and $30 \mathrm{~g}(0.114 \mathrm{~mol})$ of 9-heptylcarbazole 3 was added. The reaction mixture was heated to $90^{\circ} \mathrm{C}$ and kept it at this temperature for $24 \mathrm{~h}$. It was then poured into $500 \mathrm{ml}$ of water and extracted with chloroform. The chloroform solution was washed with water. After removal of chloroform, the crude sample with a deep color was obtained. Purification of the crude sample on a silica gel column using hexane/ethyl acetate $(7: 3)$ as an eluent yielded $15 \mathrm{~g}$ $(42 \%)$ of pure $4: \mathrm{mp} 128^{\circ} \mathrm{C}$. ${ }^{1} \mathrm{H} \mathrm{NMR}\left(\mathrm{CDCl}_{3} / \mathrm{TMS}\right)$ : $\delta(\mathrm{ppm})=10.13(2 \mathrm{H}, \mathrm{s}, 2 \times \mathrm{CHO}), 8.66\left(2 \mathrm{H}, \mathrm{d}, \mathrm{H}_{\mathrm{cz}}, J_{1}\right.$ $=1.3 \mathrm{~Hz}), 8.09\left(2 \mathrm{H}, \mathrm{dd}, \mathrm{H}_{\mathrm{cz}}, J_{1}=1.3 \mathrm{~Hz}, J_{2}=8.6 \mathrm{~Hz}\right), 7.55$ $\left(2 \mathrm{H}, \mathrm{d}, \mathrm{H}_{\mathrm{cz}}, J_{2}=8.6 \mathrm{~Hz}\right), 4.38\left(2 \mathrm{H}, \mathrm{t}, \mathrm{NCH}_{2}\right), 1.92(2 \mathrm{H}$, $\left.\mathrm{m}, \mathrm{CH}_{2}\right), 1.27\left(8 \mathrm{H}, \mathrm{m}, 4 \times \mathrm{CH}_{2}\right), 0.86\left(3 \mathrm{H}, \mathrm{t}, \mathrm{CH}_{3}\right) . \mathrm{IR}$ $(\mathrm{KBr}): v\left(\mathrm{~cm}^{-1}\right)=2955,2858($ aliph. $\mathrm{CH}), 1687(\mathrm{C}=\mathrm{O})$, 1628, 1593 (carbazole ring); Anal. Calcd for $\mathrm{C}_{21} \mathrm{H}_{23} \mathrm{NO}_{2}$ : C, $78.50 \%$; H, 7.17\%; N, 4.36\%. Found: C, 78.27\%; H, $7.32 \% ; \mathrm{N}, 4.23 \%$.

3,6-Hydroxymethyl-9-heptylcarbazole 5. To a solution of $5 \mathrm{~g}$ (15.58 $\mathrm{mmol})$ of 3,6-diformyl-9-heptylcarbazole 4 in $150 \mathrm{ml}$ of ethanol at room temperature was added $1.2 \mathrm{~g}$ $(31.58 \mathrm{mmol})$ of sodium borohydride in $5 \mathrm{ml}$ of $0.1 \mathrm{M}$ sodium hydroxide solution. The reaction was carried out at room temperature for $4 \mathrm{~h}$. The reaction mixture was poured into $1000 \mathrm{ml}$ of water. White solid sample was obtained and recrystallized from ethanol/water to give $4.7 \mathrm{~g}(92.9 \%)$ of pure 5: $\mathrm{mp} 130{ }^{\circ} \mathrm{C} ;{ }^{1} \mathrm{H} \mathrm{NMR}\left(\mathrm{CDCl}_{3} /\right.$ TMS $): \delta(\mathrm{ppm})=8.08\left(2 \mathrm{H}, \mathrm{d}, \mathrm{H}_{\mathrm{cz}}, J_{1}=1.3 \mathrm{~Hz}\right), 7.50(2 \mathrm{H}$, $\left.\mathrm{dd}, \mathrm{H}_{\mathrm{cz}}, J_{1}=1.3 \mathrm{~Hz}, J_{2}=8.3 \mathrm{~Hz}\right), 7.40\left(2 \mathrm{H}, \mathrm{d}, \mathrm{H}_{\mathrm{cz}}, J_{2}=\right.$ $8.3 \mathrm{~Hz}), 4.85\left(4 \mathrm{H}, \mathrm{s}, 2 \times \mathrm{OCH}_{2}\right), 4.28\left(2 \mathrm{H}, \mathrm{t}, \mathrm{NCH}_{2}\right), 1.85$ $\left(2 \mathrm{H}, \mathrm{m}, \mathrm{CH}_{2}\right), 1.71(2 \mathrm{H}, \mathrm{s}, \mathrm{br}, 2 \times \mathrm{OH}), 1.32(8 \mathrm{H}, \mathrm{m}$, $\left.4 \times \mathrm{CH}_{2}\right), 0.85\left(3 \mathrm{H}, \mathrm{t}, \mathrm{CH}_{3}\right)$; IR $(\mathrm{KBr}): v\left(\mathrm{~cm}^{-1}\right)=3560$ (OH), 2955 (aliph. CH), 1633, 1610 (carbazole ring); Anal. Calcd for $\mathrm{C}_{21} \mathrm{H}_{27} \mathrm{NO}_{2}$ : C, $77.54 \% ; \mathrm{H}, 8.31 \%$; N, $4.31 \%$. Found: C, $77.39 \%$; H, 8.46\%; N, 4.16\%.

3,6-Cyanoacetoxymethyl-9-heptylcarbazole 6. To a solution $4 \mathrm{~g}$ (12.30 mmol) of 3,6-dihydroxymethyl-9heptylcarbazole 5 and $2.2 \mathrm{~g}(25.88 \mathrm{mmol})$ of cyanoacetic acid in $100 \mathrm{ml}$ of dichloromethane at $0^{\circ} \mathrm{C}$ was added $5.3 \mathrm{~g}$ $(25.73 \mathrm{mmol})$ of $N, N^{\prime}$-dicyclohexylcarbodiinide (DCC). The reaction mixture was carried out at $0^{\circ} \mathrm{C}$ for $4 \mathrm{~h}$. Dicylohexylurea was separated from tetrahydrofuran (THF) solution by filtration. After removal of the solvent, the resulting residue was purified by a silica gel column using hexane/ethyl acetate $(7: 3)$ as an eluent, yielding $5.2 \mathrm{~g}(92 \%)$ of pure 6 in a white color: $\mathrm{mp} 88^{\circ} \mathrm{C} ;{ }^{1} \mathrm{H}$ NMR $\left(\mathrm{CDCl}_{3} / \mathrm{TMS}\right): \delta(\mathrm{ppm})=8.12\left(2 \mathrm{H}, \mathrm{d}, \mathrm{H}_{\mathrm{cz}}\right.$, $\left.J_{1}=1.6 \mathrm{~Hz}\right), 7.50\left(2 \mathrm{H}, \mathrm{dd}, \mathrm{H}_{\mathrm{cz}}, J_{1}=1.6 \mathrm{~Hz}, J_{2}=8.3 \mathrm{~Hz}\right)$, $7.43\left(2 \mathrm{H}, \mathrm{d}, \mathrm{H}_{\mathrm{cz}}, J_{2}=8.3 \mathrm{~Hz}\right), 5.41\left(4 \mathrm{H}, \mathrm{s}, 2 \times \mathrm{OCH}_{2}\right)$, $4.30\left(2 \mathrm{H}, \mathrm{t}, \mathrm{NCH}_{2}\right), 3.49\left(4 \mathrm{H}, \mathrm{s}, 2 \times \mathrm{CH}_{2} \mathrm{CN}\right), 1.86(2 \mathrm{H}$, $\left.\mathrm{m}, \mathrm{CH}_{2}\right), 1.33\left(8 \mathrm{H}, \mathrm{m}, 4 \times \mathrm{CH}_{2}\right), 0.86\left(3 \mathrm{H}, \mathrm{t}, \mathrm{CH}_{3}\right)$; IR $(\mathrm{KBr}): v\left(\mathrm{~cm}^{-1}\right)=2907$ (aliph. $\left.\mathrm{CH}\right), 2226(\mathrm{CN}), 1746$ $(\mathrm{C}=\mathrm{O}), 1631,1610$ (carbazole ring); Anal. Calcd for $\mathrm{C}_{27} \mathrm{H}_{29} \mathrm{~N}_{3} \mathrm{O}_{4}$ : C, $70.59 \% ; \mathrm{H}, 6.32 \% ; \mathrm{N}, 9.15 \%$. Found: $\mathrm{C}, 70.65 \%$; H, $6.40 \%$; N, 9.12\%.

$4^{\prime}$-Nitrophenylazo- $\{N, N$-bis(2-hydroxyethyl $\left.)\right]$ aniline 9. A mixture of $14 \mathrm{~g}(0.1 \mathrm{~mol})$ of 4 -nitroailine $8,10 \mathrm{ml}$ of concentrated hydrochloric acid, $7 \mathrm{~g}(0.1 \mathrm{~mol})$ of sodium nitrite and $320 \mathrm{ml}$ of water was added dropwise to a solution of $18 \mathrm{~g}(0.1 \mathrm{~mol})$ of $N, N$-bis(2-hydroxyethyl)aniline 7 in $600 \mathrm{ml}$ of ethanol. After the addition was completed, red precipitates were separated by filtration and recrystallized twice from ethanol. Deep red crystals of 9 were obtained in $20 \mathrm{~g}(60.6 \%)$ : mp $205^{\circ} \mathrm{C} ;{ }^{1} \mathrm{H}$ NMR (dimethyl sulfoxide (DMSO)- $\left.d_{6} / \mathrm{TMS}\right): \delta(\mathrm{ppm})=$ $8.32\left(2 \mathrm{H}, \mathrm{d}, \mathrm{H}_{\text {arom }}, J=8.6 \mathrm{~Hz}\right), 7.90\left(2 \mathrm{H}, \mathrm{d}, \mathrm{H}_{\text {arom }}\right.$, $J=8.6 \mathrm{~Hz}), 7.78\left(2 \mathrm{H}, \mathrm{d}, \mathrm{H}_{\text {arom }}, J=8.8 \mathrm{~Hz}\right), 6.75(2 \mathrm{H}, \mathrm{d}$, $\left.\mathrm{H}_{\text {arom }}, J=8.8 \mathrm{~Hz}\right), 4.76(2 \mathrm{H}, \mathrm{s}, \mathrm{br}, 2 \times \mathrm{OH}), 3.60(8 \mathrm{H}, \mathrm{s}$, br, $\left.4 \times \mathrm{CH}_{2}\right)$; IR $(\mathrm{KBr}): v\left(\mathrm{~cm}^{-1}\right)=3286(\mathrm{OH}), 2980$ (aliph. CH) 1600, 1590 (aromatic ring), 1510, $1350\left(\mathrm{NO}_{2}\right)$.

$4^{\prime}$-Nitrophenylazo- $\{N, N$-bis(2-cyanoacetoxyethyl $\left.)\right\}$ aniline 10. To a solution of $2 \mathrm{~g}(6.06 \mathrm{mmol})$ of $4^{\prime}$-nitrophenylazo- $\{N, N$-bis(2-hydroxyethyl)]aniline 9 and 1.2 $(14.12 \mathrm{mmol})$ of cyanoacetic acid in $100 \mathrm{ml}$ of THF at $0{ }^{\circ} \mathrm{C}$ was added $2.91 \mathrm{~g}(14.12 \mathrm{mmol})$ of DCC. This reaction mixture was kept at $0{ }^{\circ} \mathrm{C}$ for $6 \mathrm{~h}$. Dicylohexylurea was filtered off from tetrahydrofuran solution. After removal of the solvent, the resulting residue was purified by a silica gel column using hexane/ethyl acetate $(1: 1)$ as an eluent, yielding $2.4 \mathrm{~g}(85.7 \%)$ of pure 10 in a red color: $\mathrm{mp} 132{ }^{\circ} \mathrm{C} ;{ }^{1} \mathrm{H}$ NMR $\left(\mathrm{CDCl}_{3} / \mathrm{TMS}\right): \delta(\mathrm{ppm})=$ $8.34\left(2 \mathrm{H}, \mathrm{d}, \mathrm{H}_{\text {arom }}, J=8.9 \mathrm{~Hz}\right), 7.96\left(2 \mathrm{H}, \mathrm{d}, \mathrm{H}_{\text {arom }}, J=\right.$ $8.9 \mathrm{~Hz}), 7.93\left(2 \mathrm{H}, \mathrm{d}, \mathrm{H}_{\text {arom }}, J=8.9 \mathrm{~Hz}\right), 6.86\left(2 \mathrm{H}, \mathrm{d}, \mathrm{H}_{\text {arom }}\right.$, $J=8.9 \mathrm{~Hz}), 4.49\left(4 \mathrm{H}, \mathrm{t}, 2 \times \mathrm{OCH}_{2}, J=5.6 \mathrm{~Hz}\right), 3.87(4 \mathrm{H}$, $\left.\mathrm{t}, 2 \times \mathrm{NCH}_{2}, \quad J=5.6 \mathrm{~Hz}\right), 3.46\left(4 \mathrm{H}, \mathrm{s}, 2 \times \mathrm{CH}_{2} \mathrm{CN}\right)$; IR $(\mathrm{KBr}): v\left(\mathrm{~cm}^{-1)}=2926\right.$ (aliph. $\left.\mathrm{CH}\right), 2223(\mathrm{CN})$, $1746(\mathrm{C}=\mathrm{O}), 1603$ (aromatic rings), 1516, $1342\left(\mathrm{NO}_{2}\right)$; Anal. Calcd for $\mathrm{C}_{22} \mathrm{H}_{20} \mathrm{~N}_{6} \mathrm{O}_{6}: \mathrm{C}, 5690 \% ; \mathrm{H}, 4.31 \% ; \mathrm{N}$, $18.10 \%$. Found: C, $56.75 \%$; H, $4.38 \%$; N $17.97 \%$.

\section{Two-Stage Polycondensation}

All main-chain copolymers 11a-11c were synthesized from 3,6-diformyl-9-heptylcarbazole 4 and bis(cyanoacetate)s 6 or 10 by a two-stage Knoevenagel polycondensation. As a representative example, polycondensation of $\mathbf{4}$ and $\mathbf{1 0}$ is described here.

Main-Chain Polymer 11a. To a solution of $0.346 \mathrm{~g}$ (1.08 mmol) of 3,6-diformyl-9-heptylcarbazole 4 and $0.500 \mathrm{~g}(1.08 \mathrm{mmol})$ of $4^{\prime}$-nitrophenylazo- $\{N, N$-bis $(2-$ cyanoacetoxyethyl)] aniline 10 in $70 \mathrm{ml}$ of THF, $0.5 \mathrm{~g}$ of 4- $(N, N$-dimethylamino)pyridine (DMAP) was added in one portion. After the reaction mixture was stirred at $40^{\circ} \mathrm{C}$ for $1 \mathrm{~h}$, THF was removed by nitrogen purge or under reduced pressure. The polycondensation was continued at $40^{\circ} \mathrm{C}$ in solid-state for $4 \mathrm{~h}$ with nitrogen purge. After removing the DMAP and low molecular weight moieties by washing with ethyl acetate, the deep red insoluble polymer could be obtained. The yield was $0.79 \mathrm{~g}$ (99\%). IR (KBr): $v\left(\mathrm{~cm}^{-1}\right)=2957$ (alkyl chain), $2222(\mathrm{CN})$, $1714(\mathrm{C}=\mathrm{O}), 1599$ (aromatic rings), 1514, $1340\left(\mathrm{NO}_{2}\right)$.

Main-Chain Polymer 11b. Polymer 11b was prepared in $97 \%$ yield from $0.500 \mathrm{~g}(1.56 \mathrm{mmol})$ of $4,0.357 \mathrm{~g}$ 
(0.778 mmol) of 3,6-dicyanoacetoxymethyl-9-heptylcarbazole 6 and $0.361 \mathrm{~g}(0.778 \mathrm{mmol})$ of 10 using $0.5 \mathrm{~g}$ of DMAP as a base. Polymer was purified by multiple reprecipitations from a chloroform solution into hexane/ ethyl acetate $(1: 1)$. IR $(\mathrm{KBr}): v\left(\mathrm{~cm}^{-1}\right)=2955$ (alkyl chain), $1711(\mathrm{C}=\mathrm{O}), 1584$ (aromatic rings), 1516, 1339 $\left(\mathrm{NO}_{2}\right)$.

Main-Chain Polymer 11c. Polymer 11c was obtained in $99 \%$ yield from $0.250 \mathrm{~g}(0.779 \mathrm{mmol})$ of $4,0.238 \mathrm{~g}$ $(0.519 \mathrm{mmol})$ of $\mathbf{6}$ and $0.120 \mathrm{~g}(0.259 \mathrm{mmol})$ of $\mathbf{1 0}$ using $0.3 \mathrm{~g}$ of DMAP as a base. This polymer was purifed in a manner similar to polymer 11b. IR $(\mathrm{KBr}): v\left(\mathrm{~cm}^{-1}\right)=$ 2955 (alkyl chain), $1711(\mathrm{C}=\mathrm{O}), 1581$ (aromatic rings), $1514,1339\left(\mathrm{NO}_{2}\right)$

\section{Film Preparation}

The polymers were dissolved in chloroform at a concentration of $10 \mathrm{mg} \mathrm{ml}^{-1}$. The solutions were filtered through a $0.45 \mu \mathrm{m}$ filter. About $0.1 \mu \mathrm{m}$ thick films could be obtained on glass substrates by a spin coating method. The polymer films were dried at room temperature in vacuum for 2 days.

\section{Measurements}

All melting points (m.p.) were determined with a Perkin-Elmer DSC-7 at a heating rate of $1{ }^{\circ} \mathrm{Cmin}^{-1}$ in aluminum pans under nitrogen. Fourier transform infrared (FT-IR) spectra were recorded on a Shimadzu FT-IR-4100 spectrophotometer. Ultraviolet (UV) spectra were recorded with a Shimadzu UV-3100 spectrophotometer. Nuclear magnetic resonance (NMR) spectra were obtained using a JEOL JNM-EX270 spectrometer operating at $270 \mathrm{MHz}$ in $\mathrm{CDCl}_{3}$. Chemical shifts were in parts per million $(\delta)$ from internal tetramethylsilane.
NMR results were reported as chemical shifts (integration, multiplicity, assignment). The following abbreviations were used to describe the multiplicity and assignment: s (singlet), d (doublet), t (triplet), m (complex multiplet), br (broad), cz (carbazole), and arom (aromatic rings). Differential scanning calorimetries (DSC) were performed on a Perkin-Elmer DSC-7 instrument at a heating rate of $10^{\circ} \mathrm{C} \mathrm{min}^{-1}$. DSC samples were encapsulated in aluminum pans and scanned under nitrogen, an empty aluminum pan was used as a reference. Gel permeation chromatography was run at room temperature with chloroform as a solvent. The columns employed were: $10^{5} \AA, 10^{4} \AA$, and $500 \AA$ (Ultrastyragel column) combined with a JASCD 857-UV detector. The flow rate of the solvent generated by the JASCD 880 PU system was $1 \mathrm{ml} \mathrm{min}^{-1}$. Polystyrene standards with molar masses from $1.32 \times 10^{3}$ up to $3.15 \times 10^{6} \mathrm{~g} \mathrm{~mol}^{-1}$ were used for calibration of the columns. Film thicknesses were measured with a Dektak IIA surface profiler. Elemental analyses were performed in RIKEN Microanalytical Laboratroy.

\section{RESULTS AND DISCUSSION}

\section{Preparation of Monomer}

The comonomers, 3,6-diformylcarbazole 4 and bis(cyanoacetate)s $\mathbf{6}$ and $\mathbf{1 0}$ were synthesized as shown in Schemes 1 and 2. Carbazole 1 reacted with 7-bromoheptane 2 in water/benzene using $\mathrm{NaOH}$ as a base and benzyltriethylammonium chloride as a phase transfer catalyst to afford 9-heptylcarbazole 3 . Two formyl groups could be introduced to the 3 and 6 positions of carbazole 3 to yield 3,6-diformyl-9-heptylcarbazole 4 by the Vilsmeyer formylation. 3,6-Dihydroxymethyl-9-heptyl-
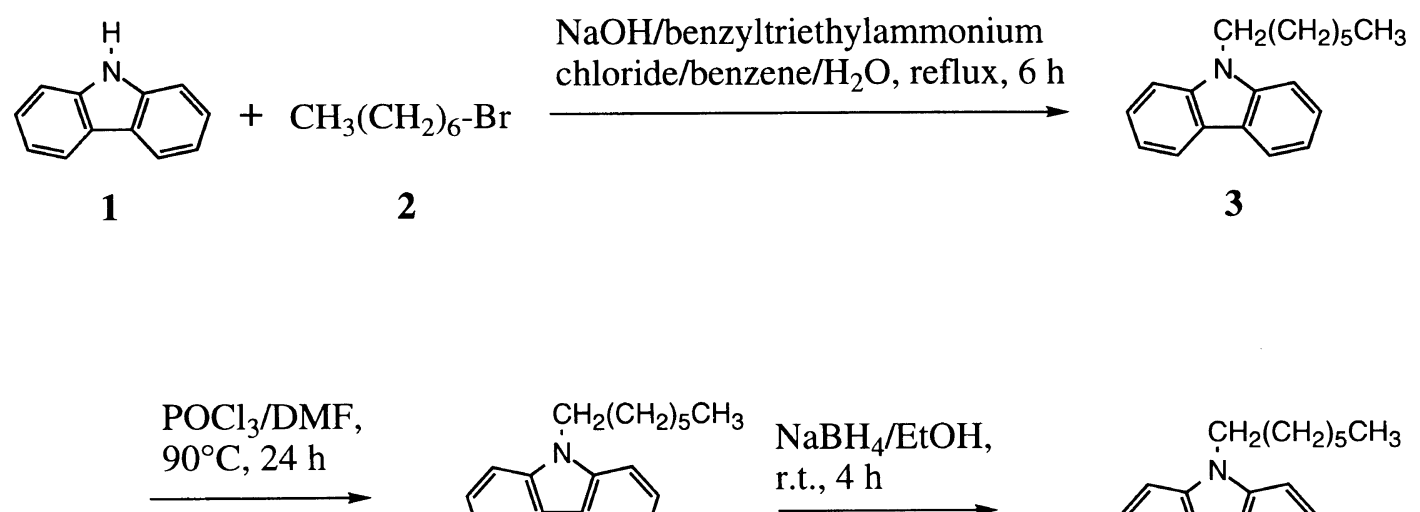

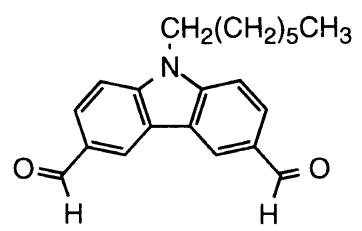

4
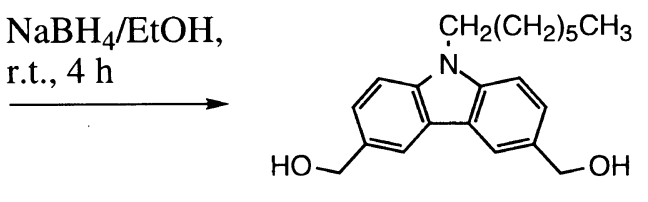

5
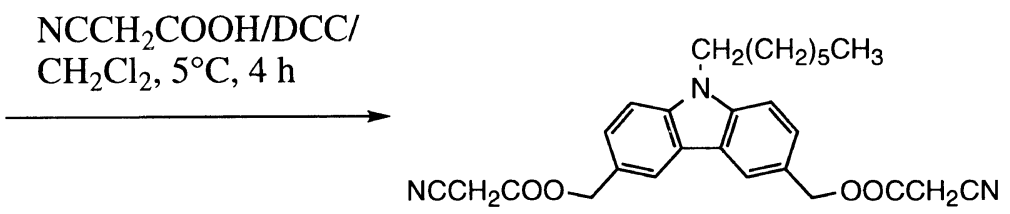

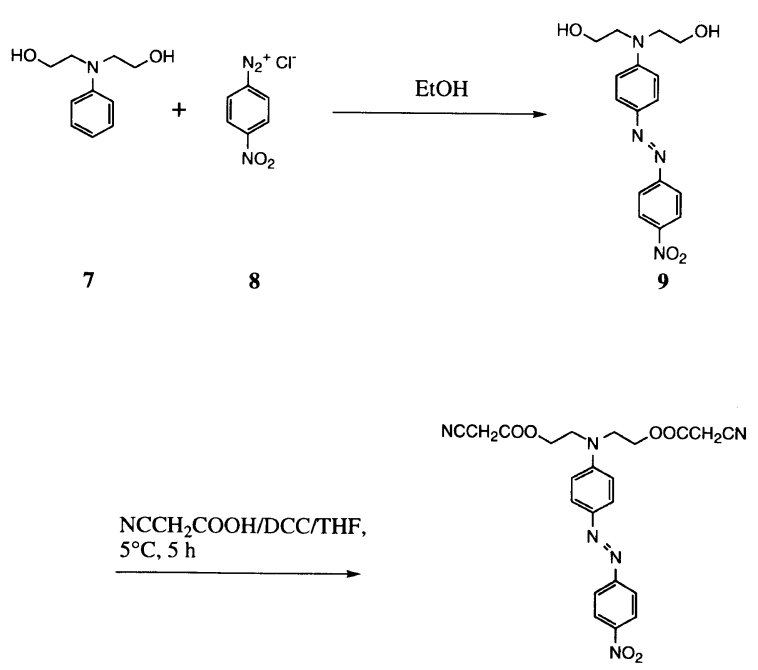

10

Scheme 2.
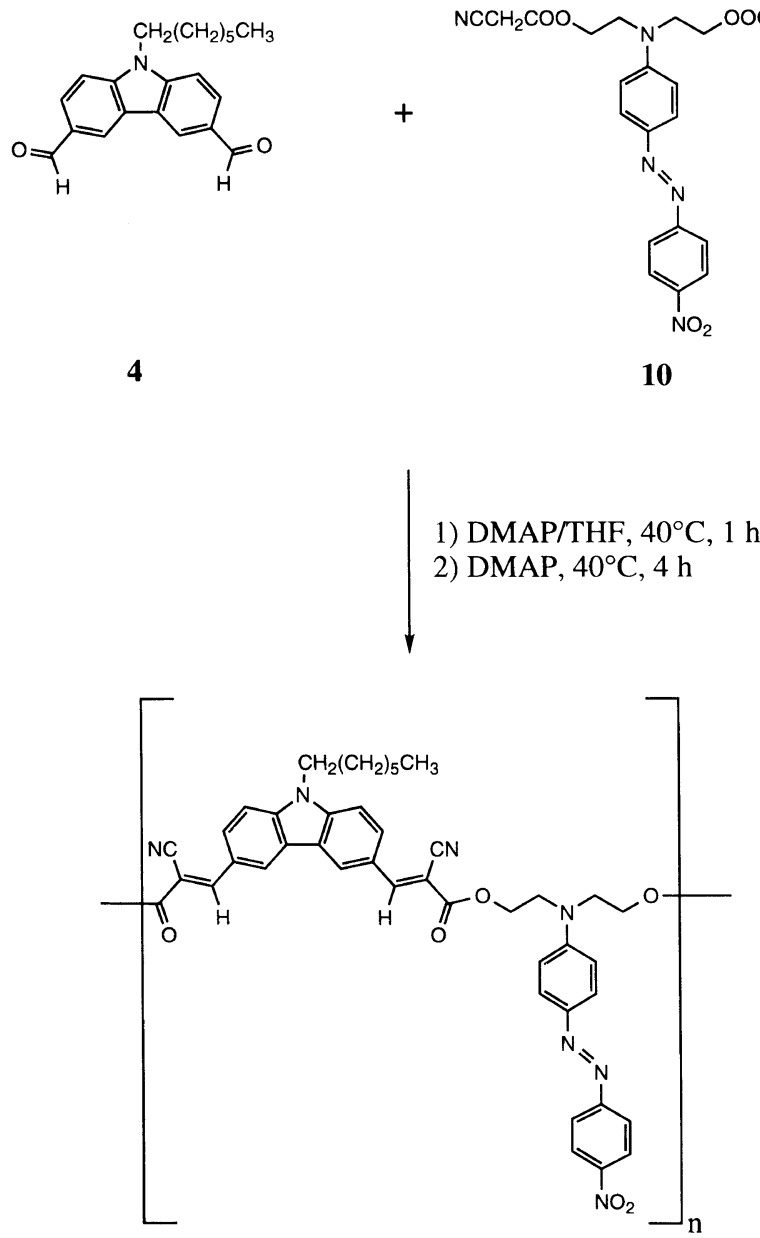

$11 \mathbf{a}$

Scheme 3.

carbazole 5 was obtained by treatment of 4 with $\mathrm{NaBH}_{4}$. Compound 5 was reacted with cyanoacetic acid in dichloromethane using DCC as a water acceptor to give bis(cyanoacetate) 6 . Compound 9 was synthesized by the azo coupling of diazonium salts of $p$-nitroaniline $\mathbf{8}$ with amine 7. Esterification of 9 with cyanoacetic acid in THF using DCC as a water acceptor yielded bis(cyanoacetate) 10. All monomers were confirmed by ${ }^{1} \mathrm{H}$ NMR, IR, and elemental analysis as shown in EXPERIMENTAL Section.

\section{Two-Stage Knoevenagel Polycondensation}

Schemes 3 and 4 show the synthesis of polymers 11ac by a two-stage Knoevenagel polycondensation from 3,6-diformylcarbazole 4 and bis(cyanoacetate)s 6 or/ and 10 using 4-dimethylaminopyridine as a base. It was found that the molecular weights and yields of these polymers were very dependent on the conditions of the polycondensation. The polycondensation carried out in THF solution yielded polymers 11a-c in very low yields. However, the two-stage polycondensation in THF solution for $1 \mathrm{~h}$, followed by the solid-state polycondensation for $4 \mathrm{~h}$ yielded polymers 11a-c in very high yields. In the case of the polycondensation of $\mathbf{4}$ and 10 (as shown in Scheme 3), insoluble polymer 11a was obtained. In order to obtain soluble polymer, the flexible moiety 6 has to be introduced to improve the solubility of the polymer (as shown Scheme 4).

$\mathrm{X}: \mathrm{Y}$ (percentage of incorporation) was obtained from molar ratio of starting materials used for the polycondensation. Polymer 11a with $X=0$ has the highest density of the NLO chromophores. In this polymer, 3,6-diacceptor-substituted carbazole and azo dye are in the polymeric main chain in a slipped shoulder-toshoulder arrangement. This polymer was found to be insoluble in common organic solvents. From polymer 11a, the thin films for NLO measurement and characterization data could not be obtained. However, this synthetic approach offered one way from which the polymers with high densities of the NLO chromophores could be obtained. In order to obtain soluble polymers, two approaches can be used to improve the solubility of polymer 11a. One is extension of the flexible alkyl chain on the 9-position of the carbazole ring, and another is addition of some flexible moieties as shown in this synthetic work. It is well known that the carbazole components are an ideal building block for multifunctional materials such as photorefractive materials. Carbazole flexible moiety 6 was selected for the synthesis of polymers due to its photoconductive properties. According to this design, polymers 11 with both photoconductivity and second-order NLO activity should show photorefractive properties. Polymers 11b and 11c with different percentages of the carbazole flexible moiety are very soluble in common organic solvents such as chloroform. The solubilities of the polymers in chloroform were summarized in Table I.

\section{Polymer Characterization}

The chemical structures of the chloroform soluble polymers, 11b and 11c, were confirmed by means of IR and ${ }^{1} \mathrm{H}$ NMR spectroscopy. Polymer 11a was only characterized by IR due to its poor solubility in common organic solvents. IR spectral data for polymers are given in Experimental Section, in which peaks due to the nitro group can be observed around 1520 and $1350 \mathrm{~cm}^{-1}$. The carbonyl peak appears at about $1720 \mathrm{~cm}^{-1}$. The peak band due to the cyano group is around $2220 \mathrm{~cm}^{-1}$. The sharp peak at about $2950 \mathrm{~cm}^{-1}$ for polymers due to flexible alkyl chain can be observed. Figure 2 shows ${ }^{1} \mathrm{H}$ 
<smiles>CCCCCn1c2ccc(C=O)cc2c2cc(C=O)ccc21</smiles>

1) DMAP/THF, $40^{\circ} \mathrm{C}, 1 \mathrm{~h}$

2) DMAP, $40^{\circ} \mathrm{C}, 4 \mathrm{~h}$

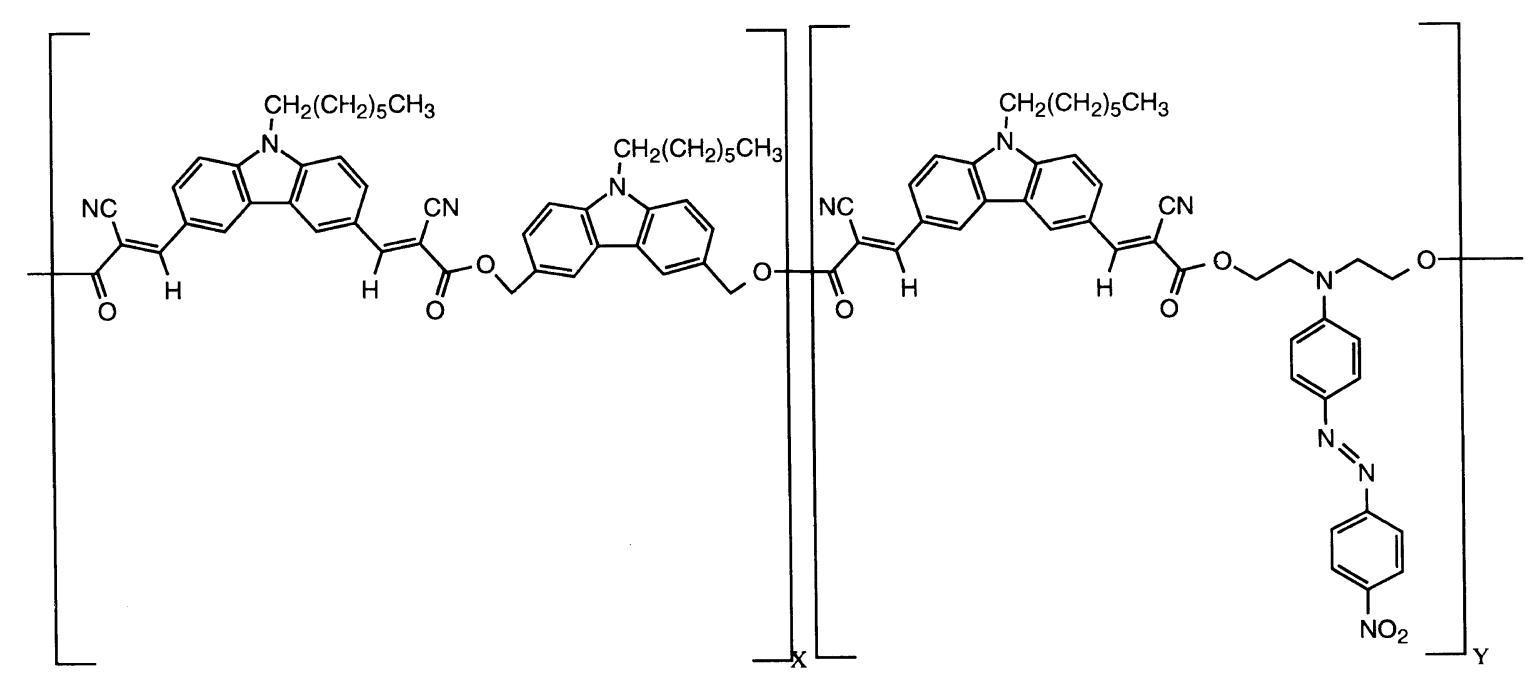

11b; $X=50, Y=50$

11c; $X=75, Y=25$

Scheme 4.

Table I. Properties of the main chain polymers 11a-c

\begin{tabular}{|c|c|c|c|c|c|}
\hline \multirow{2}{*}{ Polymer } & \multirow{2}{*}{$X: Y$} & $M_{w}$ & $M_{n}$ & $T_{\mathrm{g}}$ & \multirow{2}{*}{$\begin{array}{l}\text { Solubility } \\
\mathrm{CHCl}_{3}\end{array}$} \\
\hline & & $\mathrm{g} \mathrm{mol}^{-1}$ & $\mathrm{~g} \mathrm{~mol}^{-1}$ & ${ }^{\circ} \mathrm{C}$ & \\
\hline $11 \mathrm{a}$ & $0: 100$ & - & & 135 & - \\
\hline 11b & $50: 50$ & 3800000 & 123000 & 154 & + \\
\hline $11 \mathrm{c}$ & $75: 25$ & 4200000 & 142000 & 152 & + \\
\hline
\end{tabular}

NMR spectra of polymers $11 \mathbf{b}$ and 11c, in which the assignments are consistent with the chemical structure drawn. For polymers 11b and 11c, the chemical shifts of the methylene groups in the azo dye unit appear at 4.02 and $4.60 \mathrm{ppm}$, respectively. The spectra show the chemical shifts of the flexible chain at $0.85,1.38,1.68$, and $4.18 \mathrm{ppm}$. The chemical shift due to the protons of the methlene group in carbazole moiety appear at $5.48 \mathrm{ppm}$.
The assignments of all other chemical shifts according to the expected structure are indicated in Figure 2.

UV/VIS spectra of polymers 11b and 11c, measured in chloroform solution, show absorption in the visible region as shown in Figure 3. The absorption maxima of the polymers due to carbazole substituted with two acceptor groups appear at about $421 \mathrm{~nm}$. The shoulder peak due to the azo dye chromophore can be also observed.

The thermal properties of these polymers were studied by employing DSC. Figure 4 shows DSC traces for these polymers. $T_{\mathrm{g}}$ values can be deduced and they are summarized in Table I. Among these polymers, polymer 11a without the carbazole flexible moiety should have the highest $T_{\mathrm{g}}$. However, it can be noted that the glass transition temperatures of polymers $11 \mathbf{b}$ and 11c are higher than that of polymer 11a. This can be explained 


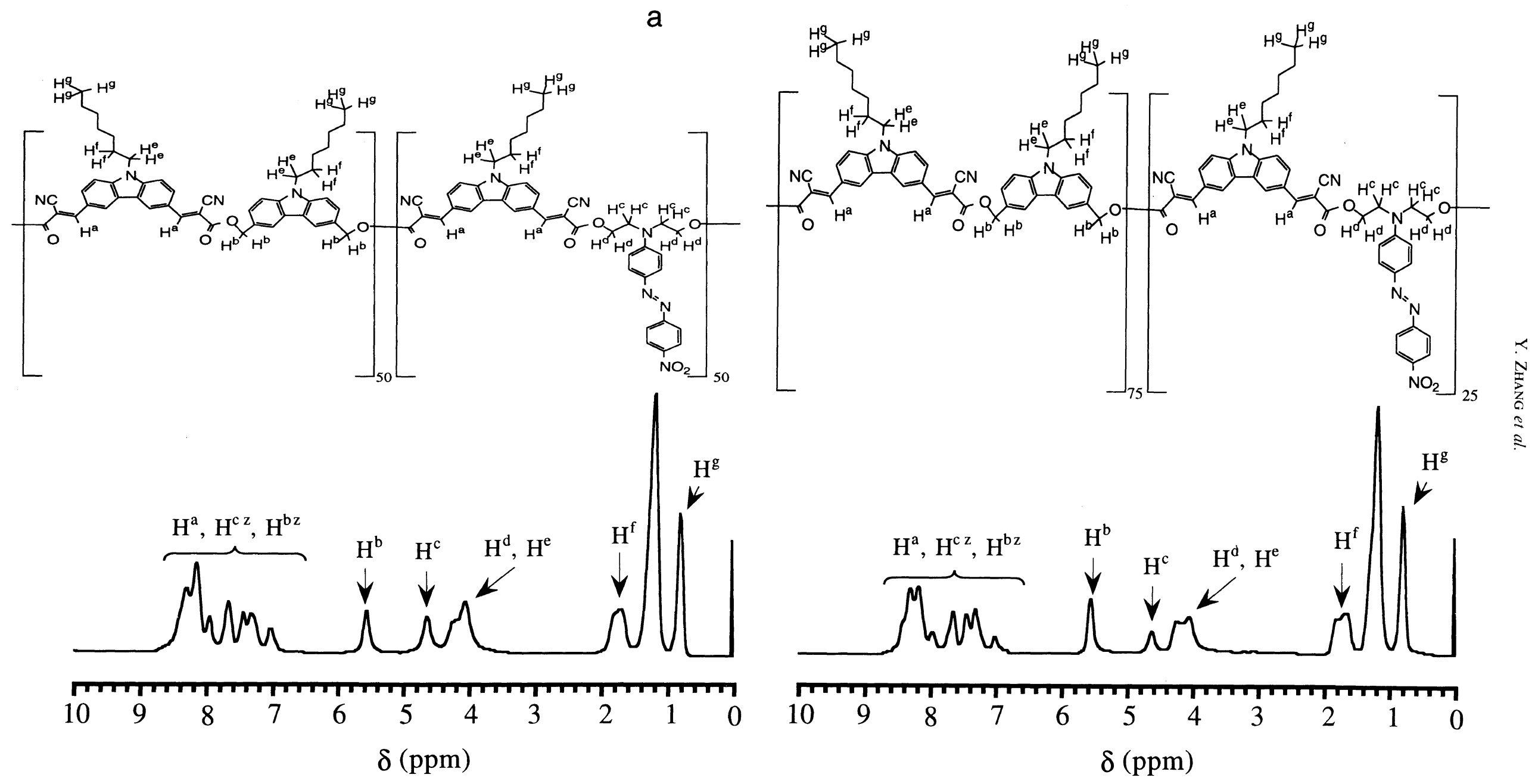

Figure 2. ${ }^{1} \mathrm{H}$ NMR $\left(\mathrm{CDCl}_{3}, 270 \mathrm{MHz}\right)$ spectra of polymers $11 \mathrm{~b}$ (a) and $\mathbf{1 1 c}(\mathrm{b})$. 


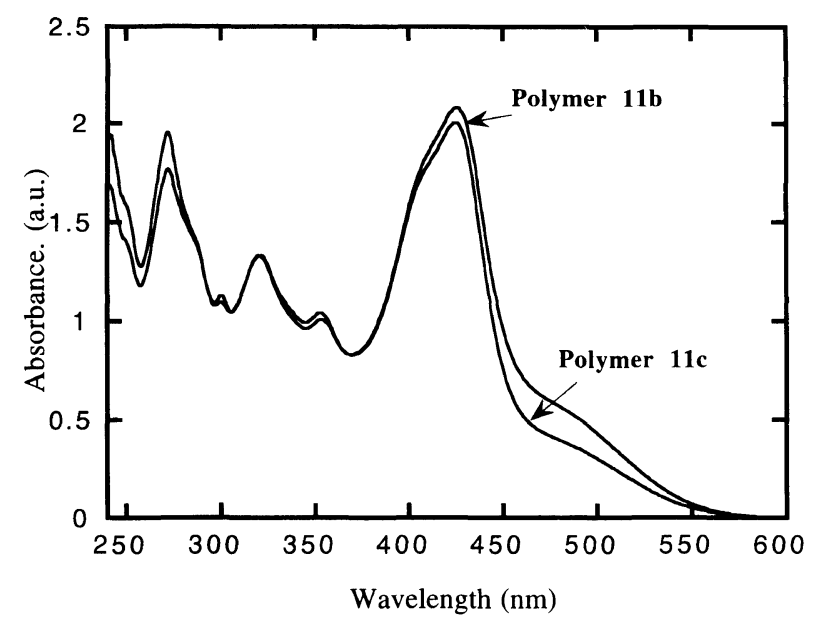

Figure 3. UV-VIS absorption spectra of polymers $11 \mathbf{b}$ and $11 \mathbf{c}$.

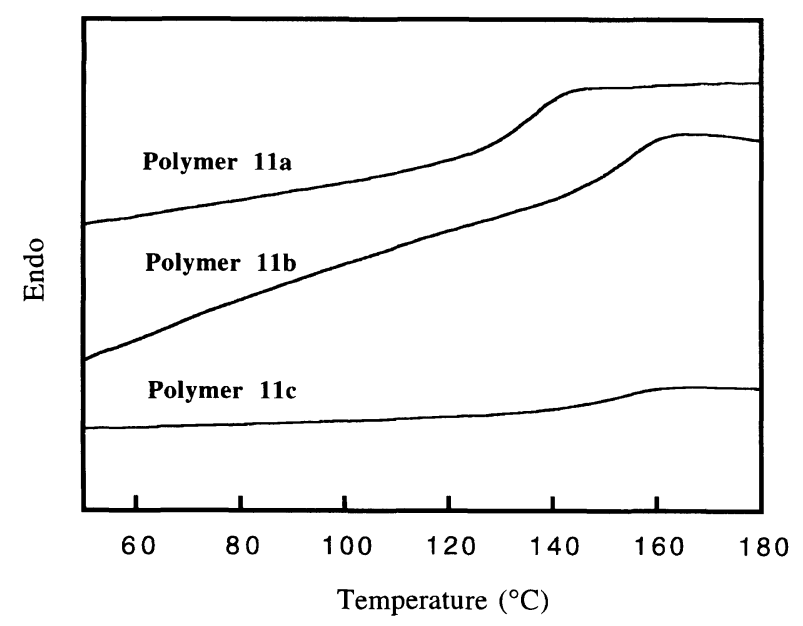

Figure 4. DSC traces of polymers $11 \mathbf{a}-\mathbf{c}$.

by a difference in the conformation of the polymer backbone. The work on the conformation of these polymers is now under study.

The average molecular weights of the chloroform soluble polymers, 11b and 11c, were determined by GPC. The GPC traces and average molecular weights are summarized in Figure 5 and Table I, respectively. It was found that polymers 11b and 11c have large molecular weights with very wide distributions. Large polydispersity of polymers might be due to the two-stage Knoevenagel polycondensation which could give polymers in high yields. However, In the solid-state polycondensation stage, polymerization was carried out inharmoniously.

\section{Alignment of NLO Chromophores}

Alignment of NLO chromophores in the main-chain polymer films were achieved by a corona-poling technique using a tungsten wire as an electrode placed 1 $\mathrm{cm}$ above the film surface to which a voltage of $15 \mathrm{kV}$ was applied. The poling was performed at $160^{\circ} \mathrm{C}$ for $60 \mathrm{~min}$ and cooled to room temperature with the electric field maintained. Figure 6 shows the absorption spectra of polymer 11c $(0.13 \mu \mathrm{m}$ thick film). It was found that the absorptions of both the carbazole $(421 \mathrm{~nm})$ and azo (shoulder) chromophores decreased after poling due to the alignment of the dipole moments of both the car-

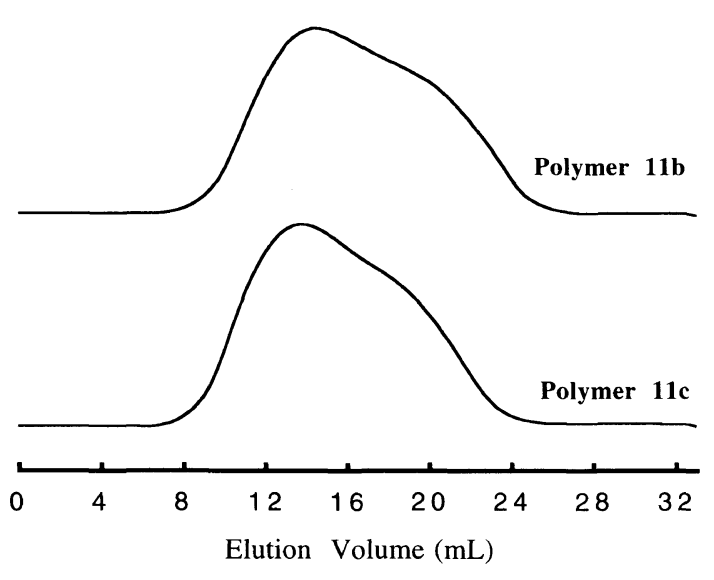

Figure 5. GPC traces of polymers $11 b$ and $\mathbf{1 1 c}$.

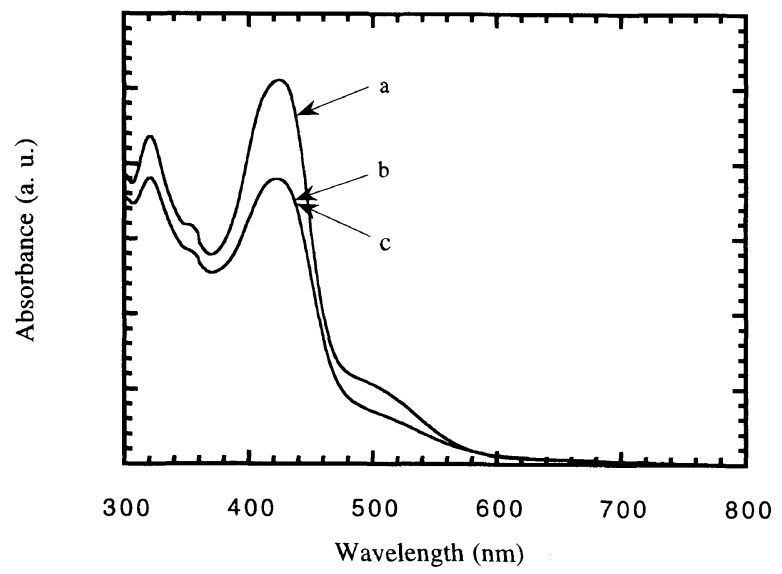

Figure 6. Absorption spectra of a polymer 11c film with $0.13 \mu \mathrm{m}$ thickness: (a) before poling; (b) shortly after poling; (c) 30 days after poling.

bazole and azo chromophores. The linear order parameter was deduced from absorption spectra using the following expression:

$$
\Phi=\left[3\left(\cos ^{2} \theta\right)-1\right] / 2=1-A_{\mathrm{p}} / A_{0}
$$

where $\theta$ is the angle between the dipole moment of the chromophore and the normal to the sample plane, $A_{0}$ and $A_{\mathrm{p}}$ are the absorbances before and after poling, respectively. The order parameter 0.26 was obtained for the carbazole chromophore. It was found that the order parameter was stable after poling without any decrease at room temperature for 30 days. The order parameter of the azo chromophore could not be obtained because the absorption maximum of the azo chromophore was overlapped with that of the carbazole chromophore. However, any change in absorption due to the shoulder part could not be observed at room temperature for 30 days after poling. This result suggests that the alignment of the azo chromophore was stable at room temperature.

\section{Nonlinear Optical Property}

The second-order optical nonlinearity of the polymer $11 c$ used as an example for the NLO study has been characterized via the second-harmonic generation (SHG). The SHG measurements were performed on poled films with $0.13 \mu \mathrm{m}$ using a Q-switched Nd-YAG laser beam $(1064 \mathrm{~nm})$. The SHG intensity of the film of polymer 11c 


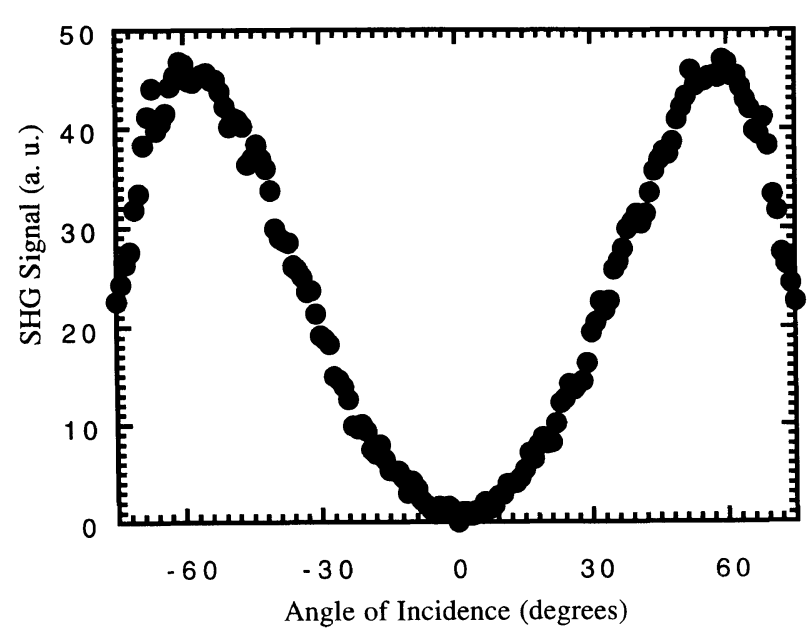

Figure 7. Maker fringe data for a polymer 11c film with $0.13 \mu \mathrm{m}$ thickness.

was measured using a standard Maker fringe technique. ${ }^{32}$ Figure 7 shows the relation between the SHG intensity and the incident angle. The second-harmonic coefficient $\left(d_{33}\right)$ of polymer 11c could be calculated from the angular dependence of the SHG intensity using the formulae of Hayden in comparison with a Y-cut quartz as a reference $\left(d_{11}=0.5 \mathrm{pm} \mathrm{V}^{-1}\right)$ signal. $^{33}$ From the calculation, we obtained a $d_{33}$ value of $60 \mathrm{pm} \mathrm{V}^{-1}$ for polymer 11c. It should be pointed out that the second-order susceptibility was resonance enhanced because of the absorption tail at the second harmonic wavelength $(532 \mathrm{~nm})$.

In summary, a new synthetic approach has been developed to incorporate second-order nonlinear optical chromophores in a high density into the polymeric main chain in which two kinds of chromophores are introduced in a slipped shoulder-to-shoulder arrangement. The poled films of these polymers show good reasonable second-order nonlinear optical responses. Preliminary results indicate that these polymers have stable secondorder nonlinear optical properties.

\section{REFERENCES}

1. D. S. Chemla and J. Zyss, "Nonlinear Optical Properties of Orgainc Molecules and Crystals," Vols. I and II, Academic Press, Inc., New York, N.Y., 1987.

2. J. F. Kasic, A. R. Kannurpatti, and C. N. Bowman, Macromol. Chem. Phys., 195, 3759 (1994).

3. R. J. Jeng, Y. M. Chen, A. K. Jain, S. K. Tripathy, and J. Kumar, Opt. Commun., 89, 212 (1992).

4. M. A. Mortazavi, A. Knoesen, S. T. Kowel, B. G. Higgins, and A. Dienes, J. Opt. Soc. Am. B, 6, 733 (1989).
5. P. Kitipichai, R. La Peruta, G. M. Korenowski, and G. E. Wnek, J. Polym. Sci., Part A, Polym. Chem., 31, 1365 (1993).

6. M. Chen, L. Yu, L. R. Dalton, Y. Shi, and W. H. Steier, Macromolecules, 24, 5421 (1991).

7. P. Rondou, M. V. Beylen, and C. Samyn, Makromol. Chem., 193, 3045 (1992).

8. H. R. Allcock, A. A. Dembek, C. Kim, R. L. S. Devine, Y. Shi, W. H. Steier, and C. W. Spangler, Macromolecules, 24, 1001 (1991).

9. M. A. Mitchell, M. Tomida, A. B. Padias, H. K. Hall, Jr., H. S. Lackritz, D. R. Robello, C. S. Willand, and D. J. Williams, Chem. Mater., 5, 1044 (1993).

10. M. E. Wright, S. Mullick, H. S. Lackritz, and L. Y. Liu, Macromolecules, 27, 3009 (1994).

11. J. J. Kulig, W. J. Brittain, S. Gilmour, and J. W. Perry, Macromolecules, 27, 4838 (1994).

12. J. D. Stenger-Smith, J. W. Fischer, R. A. Henry, J. M. Hoover, and G. A. Lindsay, Makromol. Chem., Rapid Commun., 11, 141 (1990).

13. C. Weder, P. Neuenschwander, U. W. Suter, P. Pretre, P. Kaatz, and P. Günter, Macromolecules, 27, 2181 (1994).

14. K. P. Carter, J. L. Hedrick, R. J. Twieg, T. J. Matray, and C. A. Walsh, Macromolecules, 28, 4851 (1994).

15. X. T. Tao, T. Watanabe, S. Shimoda, D. C. Zou, H. Sato, and S. Miyata, Chem. Mater., 6, 1961 (1994).

16. D. R. Robello, P. T. Dao, J. S. Schildkraut, M. Scozzafava, E. J. Urankar, and C. S. Willand, Chem. Mater., 7, 284 (1995).

17. Y. D. Zhang, L. Wang, T. Wada, and H. Sasabe, Chem. Commun., 599 (1996).

18. H. Hoegl, J. Phys. Chem., 69, 755 (1969).

19. T. Wada, Y. D. Zhang, M. Yamakado, and H. Sasabe, Mol. Cryst. Liq. Cryst., 277, 85 (1993).

20. Y. D. Zhang, T. Wada, L. Wang, T. Aoyama, and H. Sasabe, Chem. Commun., 2325 (1996).

21. B. Kippelen, K. Tamura, N. Peyghambrian, A. B. Padias, and H. K. Hall, Jr., Phys. Rev. B, 48, 10710 (1993).

22. Y. D. Zhang, T. Wada, L. Wang, T. Aoyama, and H. Sasabe, Chem. Commun., 2325 (1996)

23. K. Meerholz, B. L. Volodin, Sandalphon, B. Kippelen, and N. Peyghambarian, Nature, 371, 497 (1994).

24. G. G. Malliaras, V. V. Krasnikov, H. J. Bolink, and G. Hadziioannou, Appl. Phys. Lett., 67, 455 (1995).

25. Y. D. Zhang, L. Wang, T. Wada, and H. Sasabe, Macromolecules, 29, 1569 (1996).

26. Y. D. Zhang, L. Wang, T. Wada, and H. Sasabe, Macromol. Chem. Phys., 197, 1877 (1996).

27. Y. D. Zhang, T. Wada, and H. Sasabe, J. Polym. Sci., Part A, Polym. Chem., 34, 2298 (1996).

28. Y. D. Zhang, L. Wang, T. Wada, and H. Sasabe, J. Polym. Sci., Part A, Polym. Chem., 34, 1359 (1996)

29. Y. D. Zhang, L. Wang, T. Wada, and H. Sasabe, Macromol. Chem. Phys., 197, 667 (1996).

30. L. Wang, Y. D. Zhang, T. Wada, and H. Sasabe, Appl. Phys. Lett., 69, 728 (1996).

31. Y. D. Zhang, T. Wada, L. Wang, and H. Sasabe, Tetrahedron Lett., 38, 1785 (1997).

32. J. Jerphagnon and S. K. Kurtz, J. Appl. Phys., 41, 1667 (1970).

33. L. M. Hayden, G. F. Sauter, F. Rore, P. L. Pasillas, J. M. Hoover, G. A. Lindsay, and R. A. Henry, J. Appl. Phys., 68, 456 (1990). 